\title{
Structural Determinants of Flavin Dynamics in a Class B Monooxygenase
}

\author{
3 Ashley C. Campbell, Reeder Robinson, Didier Mena-Aguilar, Pablo Sobrado,* and John J. Tanner*
}

Cite This: https://dx.doi.org/10.1021/acs.biochem.0c00783

Read Online

4 ABSTRACT: The ornithine hydroxylase known as SidA is a class B 5 flavin monooxygenase that catalyzes the first step in the biosynthesis 6 of hydroxamate-containing siderophores in Aspergillus fumigatus. 7 Crystallographic studies of SidA revealed that the FAD undergoes 8 dramatic conformational changes between out and in states during 9 the catalytic cycle. We sought insight into the origins and purpose of 10 flavin motion in class B monooxygenases by probing the function of 11 Met101, a residue that contacts the pyrimidine ring of the in FAD. 12 Steady-state kinetic measurements showed that the mutant variant 13 M101A has a 25-fold lower turnover number. Pre-steady-state 14 kinetic measurements, $\mathrm{pH}$ profiles, and solvent kinetic isotope effect 15 measurements were used to isolate the microscopic step that is 16 responsible for the reduced steady-state activity. The data are

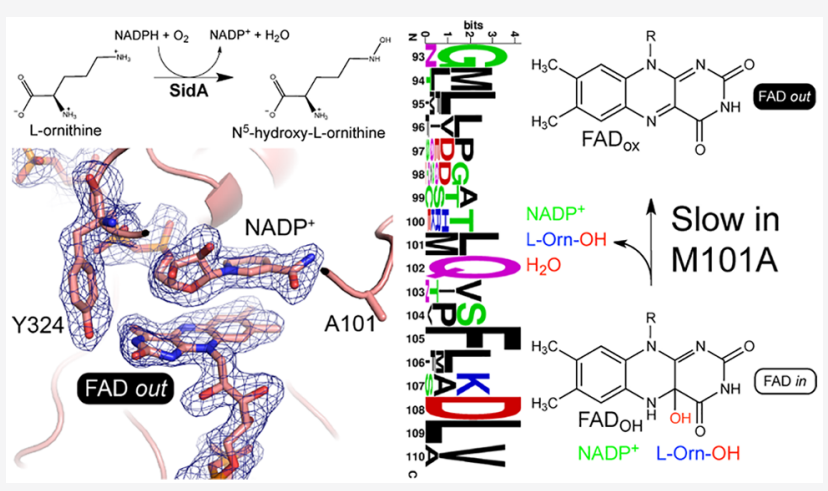
17 consistent with a bottleneck in the final step of the mechanism, which involves flavin dehydration and the release of hydroxy-L18 ornithine and $\mathrm{NADP}^{+}$. Crystal structures were determined for M101A in the resting state and complexed with NADP ${ }^{+}$. The resting 19 enzyme structure is similar to that of wild-type SidA, consistent with M101A exhibiting normal kinetics for flavin reduction by $20 \mathrm{NADPH}$ and wild-type affinity for NADPH. In contrast, the structure of the M101A-NADP ${ }^{+}$complex unexpectedly shows the FAD 21 adopting the out conformation and may represent a stalled conformation that is responsible for the slow kinetics. Altogether, our 22 data support a previous proposal that one purpose of the $\mathrm{FAD}$ conformational change from in to out in class $\mathrm{B}$ flavin 23 monooxygenases is to eject spent $\mathrm{NADP}^{+}$in preparation for a new catalytic cycle.

${ }_{23}^{u} \mathrm{~T}$ he SidA ornithine hydroxylase (UniProt E9QYP0) catalyzes the first step in the biosynthesis of hydrox26 amate-containing siderophores in the pathogenic fungus 27 Aspergillus fumigatus. ${ }^{1,2}$ The essential role of SidA in 28 siderophore biosynthesis and the lack of a sidA gene in 29 animals have motivated the development of inhibitors of SidA 30 to disable the pathogen's ability to acquire iron from the host 31 during infection production. ${ }^{3}$

32 SidA is an N-hydroxylating flavin-dependent monooxyge33 nase (NMO) that catalyzes the hydroxylation of L-ornithine ( $\mathrm{L}$ 34 Orn) to $N^{5}$-hydroxy-L-Orn (Figure 1). ${ }^{4,5}$ The multistep kinetic 35 mechanism of SidA begins with reduction of the enzyme36 bound FAD by NADPH (Figure 2). Reaction of the reduced $37 \mathrm{FAD}$ with molecular oxygen yields the C4a-hydroperoxyflavin

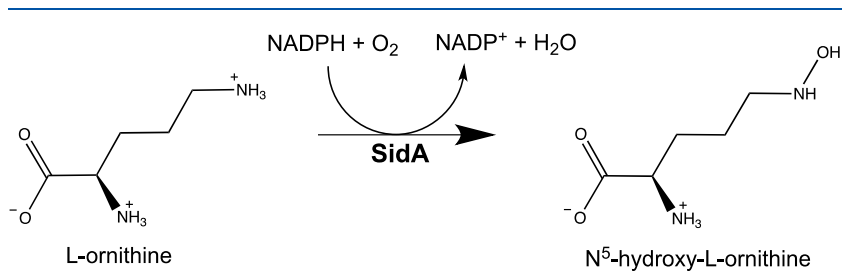

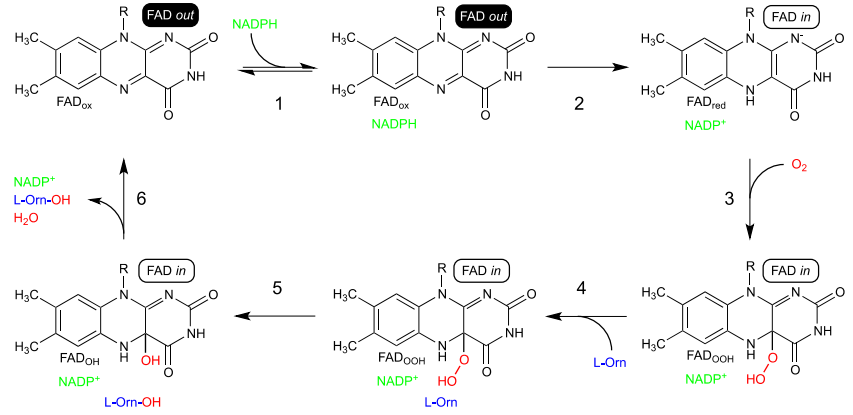

Figure 2. Kinetic mechanism of SidA. The conformation of the isoalloxazine is noted in the ovals.

intermediate $\left(\mathrm{FAD}_{\mathrm{OOH}}\right)$. L-Orn then is hydroxylated by 38 $\mathrm{FAD}_{\mathrm{OOH}}$ to generate the product $N^{5}$-hydroxy-L-Orn and 39

Received: September 22, 2020

Revised: November 9, 2020

Figure 1. Reaction catalyzed by SidA. 
$40 \mathrm{C} 4 \mathrm{a}$-hydroxyflavin. Hydrolysis of the latter and product release 41 complete the catalytic cycle. A notable feature of the 42 mechanism of SidA, as well as other class B flavin 43 monooxygenases, is that $\mathrm{NADP}^{+}$remains bound to the enzyme 44 until the final step of product release. It is thought that $\mathrm{NADP}^{+}$ 45 stabilizes the C4a-hydroperoxyflavin, preventing uncoupling of 46 the reductive and oxidative half-reactions and the release of the 47 reactive oxygen species, $\mathrm{H}_{2} \mathrm{O}_{2}{ }^{6}$.

48 Dynamics is a relatively new aspect of the mechanism of 49 SidA and other related ornithine hydroxylases. We recently 50 reported the first structure of the resting conformation of SidA, 51 i.e., the state immediately before NADPH binding (Figure 3).

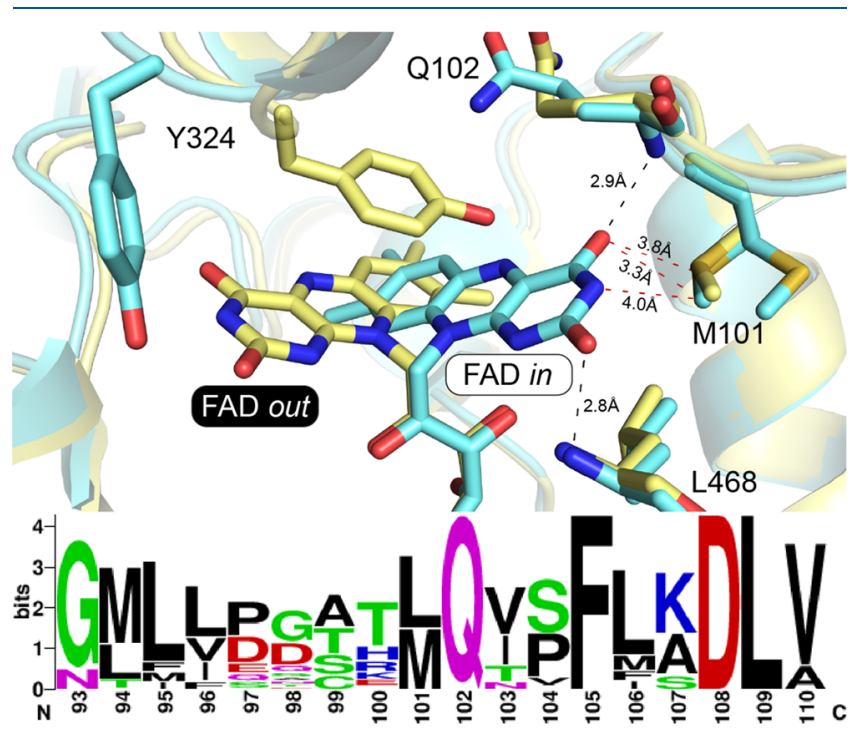

Figure 3. Comparison of the out and in conformations of wild-type SidA. Superposition of the resting conformation (yellow, PDB entry $6 \mathrm{XOH}$ ) and SidA complexed with $\mathrm{NADP}^{+}$(aquamarine, PDB entry 6X0I). The FAD is oxidized in both structures. Met101 is the residue mutated in this study. $\mathrm{NADP}^{+}$has been omitted for the sake of clarity. Black dashes denote $\mathrm{FAD}$ - protein hydrogen bonds observed in the in state. Red dashes denote close contacts between the in FAD and Met101. The sequence logo was generated from 1241 sequences with WebLogo. ${ }^{11}$

52 Remarkably, the FAD isoalloxazine of the resting state is 53 rotated out of the active site compared to other SidA structures 54 (Figure 3). Movement between the out and the more typical in 55 conformation involves dual dihedral rotations of $180^{\circ}$ and $90^{\circ}$ 56 around the $\mathrm{N} 10-\mathrm{C}^{\prime}$ and $\mathrm{C} 1^{\prime}-\mathrm{C} 2^{\prime}$ bonds of the $\mathrm{FAD}$ ribityl, 57 respectively. This motion is substantial; the pyrimidine edge of 58 the isoalloxazine moves by $9.5 \AA$. It is also catalytically relevant, 59 because the active face of the isoalloxazine ( $r$-face) is hidden 60 in the out conformation. Movement of the FAD is 61 accompanied by a $10 \AA$ conformational change of the Tyr 62 loop. In the out conformation, the eponymous residue of the 63 Tyr loop stacks against the si-face of the FAD. Either the 64 binding of $\operatorname{NADP}(\mathrm{H})$ or reduction of the FAD was sufficient 65 to promote the in conformation. A similar out FAD 66 conformation and movement of the Tyr loop were also 67 observed in crystal structures of the ornithine hydroxylase KtzI 68 (34\% identical to SidA). ${ }^{8}$ The observation of the same 69 conformational changes in the two enzymes suggests it may be 70 a conserved dynamic feature of ornithine hydroxylases. 71 Although the precise role of the out conformation in catalysis 72 remains to be determined, we suggested that the transfer of 73 hydride from NADPH to the FAD occurs with the latter in an out conformation, and that the concerted dynamics of the FAD 74 and protein allows $\mathrm{NADP}^{+}$to adopt the conformation needed 75 to stabilize C4a-hydroperoxyflavin and prevent uncou- 76 pling. ${ }^{7,9,10}$

Here, we show that an active site methionine residue of SidA 78 (Met101) is both a key determinant of the FAD conformation 79 and essential for efficient catalysis. Met101 contacts the 80 pyrimidine edge of the isoalloxazine in the in state and is 81 present in approximately half of 1241 homologous sequences 82 analyzed, including KtzI (Figure 3). The other homologues 83 contain Leu at this position; PvdA is example of this group. 84 The contacts formed by Met101 may help align the 85 isoalloxazine to form hydrogen bonds with the main chain 86 (Figure 3). We note these hydrogen bonds are also formed by 87 PvdA, suggesting that Met and Leu at this position in the chain 88 could have similar roles in stabilizing the in state. Crystal 89 structures of SidA variant M101A show that the FAD is locked 90 in the out conformation. Unlike the wild-type enzyme, the 91 binding of $\mathrm{NADP}^{+}$to M101A fails to promote the in FAD 92 conformation. Surprisingly, movement of the Tyr loop is not 93 impaired in M101A, suggesting that the mutation decoupled 94 the dynamics of the FAD from that of the protein. 95 Replacement of M101 with A does not affect the binding of 96 $\mathrm{NADPH}$ or the hydride transfer step, which is the rate-limiting 97 step in SidA. Instead, the mutation slows a step after or at the 98 same time as flavin oxidation, a step that most likely involves 99 the release of $\mathrm{NADP}^{+}$. These results provide insight into the 100 origins and purpose of active site dynamics in class B flavin 101 monooxygenases.

\section{MATERIALS AND METHODS}

Materials. Escherichia coli BL21(DE3)-Turbo chemically 104 competent cells, buffers, and media were obtained from Fisher 105 Scientific (Pittsburgh, PA). NADPH was obtained from Sigma- 106 Aldrich (St. Louis, MO), and E. coli TOP-10 chemically 107 competent cells from Invitrogen (Carlsbad, CA). Chromatog- 108 raphy columns used for protein purification were from GE 109 Healthcare. DNA primers were synthesized by Integrated 110 DNA Technologies (Coralville, IA). Plasmid preparation kits 111 were obtained from Qiagen (Valencia, CA).

112

Site-Directed Mutagenesis and Protein Production. 113 The M101 variant of the SidA construct was generated from 114 the wild-type SidA gene in pET15b. This mutation was chosen 115 as Met101 that is in the proximity of the pyrimidine edge of 116 the isoalloxazine of SidA when the flavin is in the in position 117 (Figure 3). Site-directed mutagenesis was performed using the 118 QuikChange system (Agilent Technologies) following the 119 manufacturer's instructions. For the mutagenesis reaction, the 120 forward primer (5'-CGGTATGCTGGTCCCGGGCT- 121 CGAAGGCGCAGATCAGCTTCATCAAGGATCTC-3') 122 and reverse primer (5'-GAGATCCTTGATGAAGCTGA- 123 TCTGCGCCTTCGAGCCCGGGACCAGCATACCG-3') 124 were used. The mutated gene was sequenced to ensure that the 125 mutation was incorporated. SidA M101A was expressed with 126 an N-terminal His tag followed by a thrombin cleavage site. 127

SidA M101A was expressed in E. coli and purified using 128 previously described methods. ${ }^{10}$ In brief, the protein was 129 expressed in BL21(DE3)-Turbo cells overnight at $25{ }^{\circ} \mathrm{C}$. The 130 cells were harvested by centrifugation and lysed by sonication 131 in a buffer containing $25 \mathrm{mM}$ HEPES ( $\mathrm{pH} 7.5$ ), $300 \mathrm{mM} 132$ $\mathrm{NaCl}, 25 \mathrm{mM}$ imidazole, $60 \mu \mathrm{g} / \mathrm{mL}$ lysozyme, $20 \mu \mathrm{g} / \mathrm{mL} 133$ DNase I, $20 \mu \mathrm{g} / \mathrm{mL}$ RNase, $34.2 \mathrm{mg}$ of PMSF, and $150 \mu \mathrm{M} 134$ $\mathrm{FAD}$. The lysate was centrifuged at $45000 \mathrm{~g}$ for $45 \mathrm{~min}$ at $4{ }^{\circ} \mathrm{C}$. 135 
136 The protein was purified over two $5 \mathrm{~mL}$ Ni-NTA columns 137 connected in tandem, washed with $30 \mathrm{mM}$ imidazole, and 138 eluted with $300 \mathrm{mM}$ imidazole. The His tag was cleaved using 139 thrombin as described previously. ${ }^{10}$ Briefly, thrombin $(2 \mathrm{mg} /$ $140 \mathrm{~mL}$ ) was added to the purified protein and dialyzed into a 141 buffer containing $25 \mathrm{mM}$ HEPES ( $\mathrm{pH} 7.5$ ) and $300 \mathrm{mM} \mathrm{NaCl}$, 142 and thrombin $(2 \mathrm{mg} / \mathrm{mL})$ was added and incubated overnight 143 at $4{ }^{\circ} \mathrm{C}$. Cleaved SidA M101A for crystallization was dialyzed 144 into a storage buffer containing $25 \mathrm{mM}$ HEPES ( $\mathrm{pH} 7.5$ ) and $145100 \mathrm{mM} \mathrm{NaCl}$, flash-frozen in liquid nitrogen, and stored at $146-80{ }^{\circ} \mathrm{C}$.

147 Determination of the Flavin Extinction Coefficient 148 and Incorporation. The spectra of purified M101A were 149 recorded in $100 \mathrm{mM}$ sodium phosphate ( $\mathrm{pH} \mathrm{7.5)}$. The bound 150 flavin was removed by incubating the enzyme in $9 \%(\mathrm{w} / \mathrm{v})$ $151 \mathrm{SDS}$ at $25{ }^{\circ} \mathrm{C}$ for $20 \mathrm{~min}$. After centrifugation, the free flavin 152 spectra were recorded. The extinction coefficient for M101A 153 was calculated to be $10600 \mathrm{M}^{-1} \mathrm{~cm}^{-1}$ at $458 \mathrm{~nm}$, using an 154 extinction coefficient at $450 \mathrm{~nm}$ for free FAD of $11300 \mathrm{M}^{-1}$ $155 \mathrm{~cm}^{-1} \cdot{ }^{12}$ Flavin incorporation was determined by measuring the 156 protein concentration via the Bradford assay (Bio-Rad) and 157 comparing it to the protein concentration based on the flavin 158 absorbance. Flavin incorporation was generally close to $\sim 70 \%$ 159 for M101A, which is similar to that of wild-type SidA. ${ }^{12}$

160 Steady-State Kinetics. The rate of oxygen consumption 161 was measured using a Hansatech (Norfolk, England) Oxygraph 162 system. The assay solution contained $1 \mathrm{~mL}$ of $100 \mathrm{mM}$ sodium 163 phosphate $(\mathrm{pH} 7.5)$ at $25{ }^{\circ} \mathrm{C}$. The NADPH concentration was 164 kept constant at $1 \mathrm{mM}$, while the L-Orn concentration was 165 varied between 0.1 and $15 \mathrm{mM}$. The assays were initiated by 166 addition of $5 \mu \mathrm{M}$ M101A. Reactions were monitored for $5 \mathrm{~min}$ 167 with constant stirring. Hydroxylated L-Orn was measured using 168 a variation of the Csaky iodine oxidation assay. ${ }^{12,13}$ The 169 standard assay buffer contained $104 \mu \mathrm{L}$ of $100 \mathrm{mM}$ sodium 170 phosphate ( $\mathrm{pH} 7.5)$ with varying concentrations of L-Orn and 171 the NADPH concentration held constant at $1 \mathrm{mM}$. Reactions 172 were initiated by addition of $5 \mu \mathrm{M}$ M101A. Reaction mixtures 173 were incubated for $10 \mathrm{~min}$ at $25{ }^{\circ} \mathrm{C}$ while being constantly 174 shaken at $750 \mathrm{rpm}$.

175 Pre-Steady-State Kinetics. All rapid reaction experiments 176 were carried out at $25{ }^{\circ} \mathrm{C}$ using an SX-20 stopped-flow 177 spectrophotometer (Applied Photophysics, Leatherhead, U.K.) 178 housed in an anaerobic glovebox (Coy, Grass Lake, MI). 179 Preparation of anaerobic buffer involved five cycles of $5 \mathrm{~min}$ of 180 vacuum and $1 \mathrm{~min}$ of flushing with $\mathrm{O}_{2}$-free argon for $30 \mathrm{~min}$ 181 total. The enzyme was made anaerobic by applying $1 \mathrm{~min}$ 182 cycles of vacuum and $15 \mathrm{~s}$ of flushing with $\mathrm{O}_{2}$-free argon for 5 $183 \mathrm{~min}$ total. Substrates were made anaerobic by being dissolved 184 in anaerobic buffer inside the glovebox. The stopped-flow was 185 made anaerobic by flushing with $1 \mathrm{~mL}$ of anaerobic $100 \mathrm{mM}$ 186 sodium acetate ( $\mathrm{pH} 5.0$ ) containing $100 \mathrm{mM}$ D-glucose and $187100 \mu \mathrm{g} / \mathrm{mL}$ glucose oxidase Type-X. The rate of flavin 188 reduction of M101A was measured in single mixing mode 189 where the anaerobic enzyme $(15 \mu \mathrm{M}$ after mixing) was mixed 190 with an equal volume of NADPH (15-500 $\mu \mathrm{M}$ after mixing). 191 The rate of flavin oxidation was measured in double mixing 192 mode. Anaerobic M101A (60 $\mu \mathrm{M}$ before mixing) was first 193 mixed with an equal volume of $\mathrm{NADPH}(60 \mu \mathrm{M}$ before 194 mixing). This mixture was incubated in an aging loop for $60 \mathrm{~s}$ 195 until the bound flavin was fully reduced. The reduced

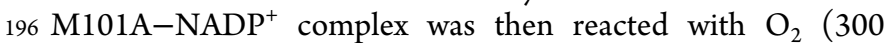
$197 \mu \mathrm{M}$ after mixing). Flavin oxidation was also performed in the 198 presence of $10 \mathrm{mM} \mathrm{L-Orn}$. Spectra were recorded on a logarithmic time scale until full reduction or oxidation was 199 completed.

pH Dependence of Flavin Oxidation. The $\mathrm{pH}$ depend- 201 ence of flavin oxidation was measured in double mixing mode. 202 Anaerobic M101A ( $60 \mu \mathrm{M}$ before mixing) was first mixed with 203 an equal volume of $\mathrm{NADPH}(60 \mu \mathrm{M}$ before mixing $)$ in $20 \mathrm{mM} 204$ Tris- $\mathrm{HCl}$ and $200 \mathrm{mM} \mathrm{NaCl}$ (pL 8.0) ( $\mathrm{pL}$ refers to the $\mathrm{pH}$ or 205 $\mathrm{pD}$ of the solution, and $\mathrm{pD}$ is equal to the $\mathrm{pH}$ value $+0.4,206$ which is the variation from the change in the equilibrium on a 207 hydrogen selective glass electrode). ${ }^{14}$ This mixture was allowed 208 to incubate in an aging loop for $60 \mathrm{~s}$ until the bound flavin was 209 fully reduced. The reduced $\mathrm{M} 101 \mathrm{~A}-\mathrm{NADP}^{+}$complex was then 210 allowed to react with air-saturated buffer. This air-saturated 211 solution contained $200 \mathrm{mM}$ buffer that rapidly increased the 212 $\mathrm{pL}$ to the desired value in the flow cell. Between $\mathrm{pL}$ values of 6213 and 8, sodium phosphate was used; between pL values of 8.5214 and 9.0, Tris-SO ${ }_{4}$ was used, and between $\mathrm{pL}$ values of 9.5 and 215 10.5 , sodium carbonate/bicarbonate was used.

216

Solvent Kinetic Isotope Effect Studies on Flavin 217 Oxidation. Solvent kinetic isotope effect (SKIE) experiments 218 were performed in the presence and absence of $15 \mathrm{mM} \mathrm{L}-\mathrm{Orn} .219$ For the reactions in $\mathrm{D}_{2} \mathrm{O}, \mathrm{M} 101 \mathrm{~A}$ was concentrated to $\sim 400220$ $\mu \mathrm{M}$ (based on flavin content) and diluted to $60 \mu \mathrm{M}$ in a $100 \% 221$ $\mathrm{D}_{2} \mathrm{O}$ buffer of $20 \mathrm{mM}$ Tris- $\mathrm{HCl}$ and $200 \mathrm{mM} \mathrm{NaCl}$ ( $\mathrm{pD} 8.0$ ). 222 This gave a concentration of $\sim 85 \% \mathrm{D}_{2} \mathrm{O}$, and after two mixes 223 in the stopped-flow with $100 \% \mathrm{D}_{2} \mathrm{O}$ buffer, a final $\mathrm{D}_{2} \mathrm{O} 224$ concentration of $\sim 96 \%$ was achieved. SKIEs in the absence 225 and presence of L-Orn were determined at $\mathrm{pL}$ values of 7.0 and 226 9.0, respectively. All solutions were checked for their proper $\mathrm{pL} 227$ values with a Fisher Scientific Accumet AB15+ Basic pH meter. 228 Spectra were recorded on a logarithmic time scale until 229 oxidation was complete.

230

Data Analysis. All data were fit using KaleidaGraph 231 (Synergy Software, Reading, PA). The rates of flavin reduction 232 were determined by fitting the decrease in absorbance at 458233 $\mathrm{nm}$ to a double-exponential decay equation (eq 1). 234

$$
v=c+a_{1} \mathrm{e}^{-k_{1} t}+a_{2} \mathrm{e}^{-k_{2} t}
$$

For flavin oxidation studies, the increase in absorbance at 236 $458 \mathrm{~nm}$, which corresponds to flavin oxidation by $\mathrm{H}_{2} \mathrm{O} 237$ elimination in the presence of L-Orn, was fit to a triple- 238 exponential rise function (eq 2). In the absence of L-Orn, a 239 double-exponential function was sufficient to model the data 240 (eq 2 with the third term omitted). The oxidation rate 241 constant measured at $458 \mathrm{~nm}$ as a function of $\mathrm{pH}$ was fit to eq 242 3. This equation describes a curve with a single $\mathrm{p} K_{\mathrm{a}}$ with 243 increasing activity as the $\mathrm{pH}$ increases and plateau regions at 244 high and low $\mathrm{pH}$. $C$ and $A$ in eq 3 represent the upper and 245 lower limits for the $\mathrm{pL}$ profile, respectively.

$$
\begin{aligned}
& v=c+a_{1}\left(1-\mathrm{e}^{-k_{1} t}\right)+a_{2}\left(1-\mathrm{e}^{-k_{2} t}\right)+a_{3}\left(1-\mathrm{e}^{-k_{3} t}\right) \\
& y=\frac{C+A\left(10^{\mathrm{p} K_{\mathrm{a}}-\mathrm{pL}}\right)}{1+10^{\mathrm{p} K_{\mathrm{a}}-\mathrm{pL}}}
\end{aligned}
$$

Crystallization, X-ray Diffraction Data Collection, and 249 Refinement. M101A was crystallized using conditions similar 250 to those described for wild-type SidA. ${ }^{7}$ Crystallization was 251 performed in sitting drops at $293 \mathrm{~K}$ with an enzyme stock 252 solution containing $8-10 \mathrm{mg} / \mathrm{mL}$ M101A in $25 \mathrm{mM}$ HEPES 253 $(\mathrm{pH} 7.5)$ and $100 \mathrm{mM} \mathrm{NaCl}$. The crystallization reservoir 254 contained 17-21\% (w/v) PEG 3350, 0.1 M HEPES (pH 7.5), 255 
256 and $0.1 \mathrm{M}$ calcium acetate. The drops were formed by mixing a 257 2:1 enzyme/reservoir solution. For crystallization of the $258 \mathrm{NADP}^{+}$complex, the enzyme stock solution contained 1 $259 \mathrm{mM} \mathrm{NADP}^{+}$. The crystals were cryoprotected in $15 \%(\mathrm{v} / \mathrm{v})$ 260 PEG 200, 20\% (w/v) PEG 3350, 0.1 M HEPES, (pH 7.5), and $2610.1 \mathrm{M}$ calcium acetate.

262 X-ray diffraction data were collected in shutterless mode at 263 ALS beamline 4.2.2. The data sets were integrated and scaled 264 with XDS. ${ }^{15}$ Intensities were converted to amplitudes with 265 AIMLESS. ${ }^{16}$ The space group is $P 2_{1}$ with the unit cell 266 dimensions listed in Table 1. The asymmetric unit contains

Table 1. Summary of X-ray Diffraction Data Collection and Refinement Statistics

\begin{tabular}{|c|c|c|}
\hline & ligand-free & $\mathrm{NADP}^{+}$ \\
\hline resolution $(\AA)^{a}$ & $61.4-2.20(2.24-2.20)$ & $62.9-2.10(2.14-2.10)$ \\
\hline mean $I / \sigma^{a}$ & $10.8(0.9)$ & $9.4(1.7)$ \\
\hline $\mathrm{CC}_{1 / 2}^{a}$ & $0.995(0.484)$ & $0.993(0.740)$ \\
\hline completeness $(\%)^{a}$ & $98.7(89.2)$ & $96.6(95.9)$ \\
\hline multiplicity $^{a}$ & $3.5(2.8)$ & $3.5(2.9)$ \\
\hline$R_{\text {cryst }}^{a}$ & $0.194(0.334)$ & $0.204(0.205)$ \\
\hline$R_{\text {free }}^{a, b}$ & $0.230(0.378)$ & $0.241(0.255)$ \\
\hline Clashscore $(\mathrm{PR})^{c}$ & 3.38 (99) & $2.94(99)$ \\
\hline $\begin{array}{l}\text { MolProbity score } \\
(P R)^{c}\end{array}$ & $1.53(98)$ & $1.25(100)$ \\
\hline \multicolumn{3}{|l|}{ average $B\left(\AA^{2}\right)$} \\
\hline protein & 35.1 & 28.8 \\
\hline FAD & 27.5 & 23.4 \\
\hline $\mathrm{NADP}^{+}$ & $\mathrm{N} / \mathrm{A}$ & 25.5 \\
\hline water & 30.1 & 26.1 \\
\hline PDB entry & 7JVK & 7JVL \\
\hline
\end{tabular}

${ }^{a}$ Values for the outer resolution shell of data are given in parentheses. ${ }^{b}$ A $2 \%$ test set. ${ }^{c}$ From MolProbity. The percentile ranks (PR) for Clashscore and MolProbity score are given in parentheses.

267 one SidA tetramer. We note this is the same crystal form that 268 we used previously to determine structures of wild-type SidA. ${ }^{17}$ 269 Data processing statistics are summarized in Table 1 and listed 270 in detail in Table S1.

271 PHENIX $^{18}$ was used for refinement, and $\operatorname{Coot}^{19}$ was used 272 for model building. The starting model for refinement was 273 derived from the coordinates of wild-type SidA (PDB entry $2746 \mathrm{X0H}$ for ligand-free M101A and PDB entry 6X0I for the $275 \mathrm{NADP}^{+}$complex). Noncrystallographic symmetry restraints 276 were used during refinement. The structures were validated 277 using MolProbity ${ }^{20}$ and the wwPDB validation server. ${ }^{21}$ Polder 278 maps were used to validate the modeling of ligands and the 279 Tyr loop. ${ }^{22}$ Refinement statistics are summarized in Table 1 280 and listed in detail in Table S1.

\section{$281 \square$ RESULTS}

282 Ultraviolet-Visible (UV-vis) Flavin Spectra of 283 M101A. The flavin spectra for M101A show some minor 284 changes in the $\lambda_{\max }$ from $450 \mathrm{~nm}$ for wild-type SidA (SidA 285 henceforth) to $458 \mathrm{~nm}$ for M101A (Figure S1). Also, the 286 extinction coefficient was decreased to $10600 \mathrm{M}^{-1} \mathrm{~cm}^{-1}$, 287 compared to a value of $13700 \mathrm{M}^{-1} \mathrm{~cm}^{-1}$ for SidA.

288 Steady-State Oxygen Consumption. The steady-state 289 kinetic parameters for oxygen consumption for M101A were 290 determined using L-Orn as the variable substrate and NADPH 291 at a saturating concentration. M101A displayed reduced 292 activity, its $k_{\text {cat }}$ value being $\sim 25$-fold lower than that of SidA
(Table 2). The $K_{\mathrm{m}}$ value for L-Orn appears to be unaffected, 293 t2 indicating that mutation of Met101 does not affect the binding 294 of L-Orn.

Table 2. Steady-State Kinetic Parameters ${ }^{a}$

\begin{tabular}{|c|c|c|}
\hline \multicolumn{3}{|c|}{ Oxygen Consumption } \\
\hline & $\operatorname{SidA}^{b}$ & M101A \\
\hline$k_{\text {cat }}\left(\mathrm{s}^{-1}\right)$ & $0.59 \pm 0.01$ & $0.023 \pm 0.002$ \\
\hline$K_{\mathrm{m}(\mathrm{L}-\mathrm{Orn})}(\mathrm{mM})$ & $1.1 \pm 0.3$ & $0.7 \pm 0.2$ \\
\hline$k_{\text {cat }} / K_{\mathrm{m} \text { (L-Orn) }}\left(\mathrm{M}^{-1} \mathrm{~s}^{-1}\right)$ & $500 \pm 100$ & $30 \pm 10$ \\
\hline \multicolumn{3}{|c|}{ L-Orn Hydroxylation } \\
\hline & $\operatorname{SidA}^{b}$ & M101A \\
\hline$k_{\text {cat }}\left(\mathrm{s}^{-1}\right)$ & $0.62 \pm 0.02$ & $0.024 \pm 0.001$ \\
\hline$K_{\mathrm{m}(\mathrm{L}-\mathrm{Orn})}(\mathrm{mM})$ & $1.0 \pm 0.2$ & $1.8 \pm 0.3$ \\
\hline$k_{\text {cat }} / K_{\mathrm{m} \text { (L-Orn) }}\left(\mathrm{M}^{-1} \mathrm{~s}^{-1}\right)$ & $600 \pm 100$ & $14 \pm 2$ \\
\hline
\end{tabular}

Steady-State L-Orn Hydroxylation. The steady-state 296 kinetic parameters for L-Orn hydroxylation for M101A were 297 calculated under saturating concentrations of NADPH. The 298 data indicate that M101A has very similar $k_{\text {cat }}$ values for L-Orn 299 hydroxylation and oxygen consumption; thus, the coupling of 300 the oxidative and reductive half-reaction is $\sim 100 \%$ and similar 301 to that of SidA (Table 2 and Figure S2).

302

Pre-Steady-State Kinetics of Flavin Reduction and 303 Oxidation. The rate constant for flavin reduction was 304 measured for M101A at varying concentrations of NADPH 305 to determine if this mutation affected the affinity for NADPH 306 or the hydride transfer step. M101A is reduced by NADPH in 307 a double-exponential manner similar to that of SidA (Figure 308 S3A). ${ }^{23,24} \mathrm{M} 101 \mathrm{~A}$ is fully reduced by NADPH, and the rate 309 constant for flavin reduction is only slightly different from that 310 of SidA (Table 3). Although under conditions tested the $K_{\mathrm{D}} 311$ t3 value could not be calculated, the fact that the maximum rate 312 of flavin reduction was observed at $15 \mu \mathrm{M}$ NADPH (Figure 313 S3B) indicates that the mutation did not substantially change 314 the $K_{\mathrm{D}}$ value for NADPH. Thus, the M101A mutation did not 315 significantly affect the rate of reduction or affinity for NADPH. 316

The oxidative half-reaction in the presence and absence of L- 317 Orn was performed to determine if the reaction with molecular 318 oxygen, stabilization of the C4a-hydroperoxyflavin intermedi- 319 ate, or flavin dehydration step was affected by the mutation. 320 Table 3 shows the rate constant for formation of the C4a- 321 hydroperoxyflavin $\left(k_{\mathrm{OOH}}\right.$, step 3 in Figure 2). Similar to SidA, 322 the reaction is enhanced when L-Orn is present for M101A. 323 The rate constants for hydrogen peroxide release $\left(k_{\mathrm{H}_{2} \mathrm{O}_{2}}\right)_{324}$ which occurs in the absence of L-Orn, show that elimination of 325 hydrogen peroxide is $\sim 2$-fold slower for M101A. In the 326 presence of L-Orn, hydroxylation occurs and the changes in 327 flavin spectra at $458 \mathrm{~nm}$ report on the dehydration of the flavin 328 $\left(k_{\mathrm{H}_{2} \mathrm{O}}\right.$, step 6 in Figure 2). The mutation of Met101 causes an 329 $\sim 14$-fold decrease in $k_{\mathrm{H}_{2} \mathrm{O}}$ (Table 3 ).

pH Profile for Flavin Oxidation in the Presence and 331 Absence of L-Orn. The $\mathrm{pH}$ profiles of flavin oxidation for 332 M101A were measured to determine if this mutation changed 333 the $\mathrm{pK}$ a value for N5 of the flavin (Table 4 and Figures S4- $334 \mathrm{t} 4$ S6). The results show similar $\mathrm{p} K_{\mathrm{a}}$ values as calculated for SidA 335 in the absence or presence of L-Orn, suggesting that Met101 336 
Table 3. Pre-Steady-State Kinetic Parameters for Flavin Reduction and Oxidation ${ }^{a}$

\begin{tabular}{|c|c|c|c|c|}
\hline \multicolumn{5}{|c|}{ Reduction } \\
\hline & \multicolumn{2}{|c|}{$k_{\text {red1 }}\left(\mathrm{s}^{-1}\right)$} & $k_{\mathrm{red} 2}\left(\mathrm{~s}^{-1}\right)$ & $K_{\mathrm{D}}(\mu \mathrm{M})$ \\
\hline $\operatorname{SidA}{ }^{b}$ & \multicolumn{2}{|c|}{$0.62 \pm 0.01$} & $0.220 \pm 0.005$ & $\sim 1$ \\
\hline M101A & \multicolumn{2}{|c|}{$0.87 \pm 0.01$} & $0.25 \pm 0.04$ & $\mathrm{~N} / \mathrm{D}$ \\
\hline \multicolumn{5}{|c|}{ Oxidation } \\
\hline & \multicolumn{2}{|c|}{$(-)$ L-Orn } & \multicolumn{2}{|c|}{$(+)$ L-Orn } \\
\hline & $k_{\mathrm{OOH}}\left(\mathrm{s}^{-1}\right)$ & $k_{\mathrm{H}_{2} \mathrm{O}_{2}}\left(\mathrm{~s}^{-1}\right)$ & $k_{\mathrm{OOH}}\left(\mathrm{s}^{-1}\right)$ & $k_{\mathrm{H}_{2} \mathrm{O}}\left(\mathrm{s}^{-1}\right)$ \\
\hline $\operatorname{SidA}^{b}$ & $0.65 \pm 0.06$ & $0.0150 \pm 0.0005$ & $18 \pm 2$ & $1.20 \pm 0.03$ \\
\hline M101A & $0.73 \pm 0.08$ & $0.0080 \pm 0.0001$ & $25 \pm 2$ & $0.084 \pm 0.007$ \\
\hline
\end{tabular}

${ }^{a}$ Conditions: $100 \mathrm{mM}$ sodium phosphate, $\mathrm{pH} 7.5$, and $25^{\circ} \mathrm{C}$. The uncertainties were calculated from three technical replicates. ${ }^{b} \mathrm{Data}$ from ref 24 .

Table 4. $\mathrm{p} K_{\mathrm{a}}$ and Solvent Kinetic Isotope Effect Values

\begin{tabular}{|c|c|c|}
\hline & $(-)$ L-Orn & $(+)$ L-Orn \\
\hline \multicolumn{3}{|c|}{$\operatorname{SidA}^{a}$} \\
\hline $\mathrm{p} K_{\mathrm{a}}, \mathrm{H}_{2} \mathrm{O}$ & $>9$ & $6.7 \pm 0.1$ \\
\hline $\mathrm{p} K_{\mathrm{a}}, \mathrm{D}_{2} \mathrm{O}$ & $>10$ & $7.18 \pm 0.05$ \\
\hline SKIE & $\begin{array}{c}2.30 \pm 0.07 \\
\mathrm{M} 101 \mathrm{~A}\end{array}$ & $1.59 \pm 0.01$ \\
\hline $\mathrm{p} K_{\curvearrowright}, \mathrm{H}_{2} \mathrm{O}$ & $>9$ & $6.9 \pm 0.1$ \\
\hline SKIE & $1.59 \pm 0.09$ & $1.35 \pm 0.08$ \\
\hline
\end{tabular}

${ }^{a}$ Data from ref 24 . The reported uncertainties are from the fitting analysis.

337 does not play a major role in regulating the $\mathrm{p} K_{\mathrm{a}}$ value of 338 residues in the active site or the flavin N5 atom.

339 Solvent Kinetic Isotope Effect. The SKIEs of flavin 340 oxidation were measured for M101A to determine if its 341 atypical oxidation kinetics are due to a chemical step becoming 342 more rate-limiting due to the mutation. Previously, we have 343 shown that the SKIEs for flavin oxidation in SidA for both 344 hydrogen peroxide and water elimination involve a proton 345 transfer originating from N5 of the flavin. ${ }^{9}$ The data indicate 346 that in the absence of L-Orn, the SKIE is lower for M101A, 347 while in the presence of L-Orn, the SKIE is only slightly lower 348 or perhaps unchanged (see Table 4 and Figure S7). This 349 suggests that for M101A, the much slower acceleration of 350 flavin oxidation when L-Orn is present is not due to water 351 elimination becoming more rate-limiting.

352 Structures of M101A. The crystal structure of M101A 353 with the FAD oxidized and no substrates bound (resting state) 354 was determined at $2.2 \AA$ resolution. Electron density clearly 355 indicated that the FAD was in the out conformation, which is 356 expected for the resting enzyme (Figure 4A). The Tyr loop 357 adopts the conformation associated with the out FAD, in which 358 Tyr324 stacks against the $s i$-face of the isoalloxazine. These 359 observations were consistent for all four protomers of the 360 tetramer in the asymmetric unit. The root-mean-square 361 deviation between the resting conformations and M101A and 362 wild-type SidA is only $0.18-0.35 \AA /$ chain. These results 363 suggest that the mutation did not perturb the resting structure 364 SidA.

365 The structure of M101A complexed with $\mathrm{NADP}^{+}$(FAD 366 oxidized) was determined at $2.1 \AA$ resolution. The electron 367 density clearly indicated the conformations of the FAD, $368 \mathrm{NADP}^{+}$, and Tyr324 (Figure 5A). Unexpectedly, the FAD 369 adopts the out conformation despite the presence of $\mathrm{NADP}^{+}$in 370 the active site. Although the FAD remains out, the Tyr loop has 371 moved to the conformation associated with the in FAD (Figure 372 5B). Movement of the Tyr loop is necessary to avoid a steric

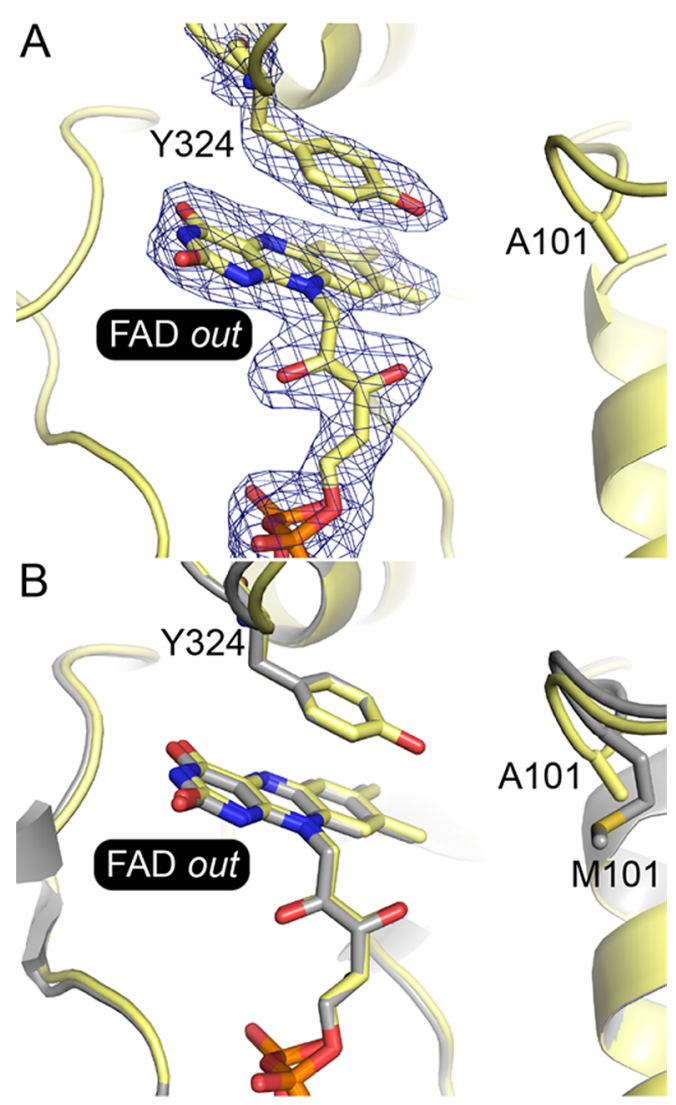

Figure 4. Structure of the resting state of M101A. (A) Electron density for the FAD and Tyr324. The mesh represents a polder omit map $(3 \sigma)$. (B) Comparison of the resting conformations of M101A (yellow) and wild-type SidA (gray, PDB entry 6X0H).

clash with $\mathrm{NADP}^{+}$. The conformation of $\mathrm{NADP}^{+}$is identical to 373 that of the wild-type enzyme; however, because the FAD is out, 374 the $\mathrm{NADP}^{+}$packs against the $s i$-face of the isoalloxazine in 375 M101A, rather than the re-face as observed in the wild-type 376 enzyme (Figure 5B).

The active site of the M101A-NADP ${ }^{+}$complex resembles 378 the dead-end inhibited complex of wild-type KtzI (PDB entry 379 4TLZ), also a class B ornithine hydroxylase (34\% identical to 380 SidA). ${ }^{8}$ In both structures, the FAD is out, $\mathrm{NADP}^{+}$is in the 381 standard conformation, and the Tyr loop adopts the 382 conformation associated with the in FAD (Figure 5C). 383

\section{DISCUSSION}

384

Flavin-dependent monooxygenases represent a large family of 385 enzymes with diverse chemical activities. ${ }^{6,25}$ The mechanism 386 


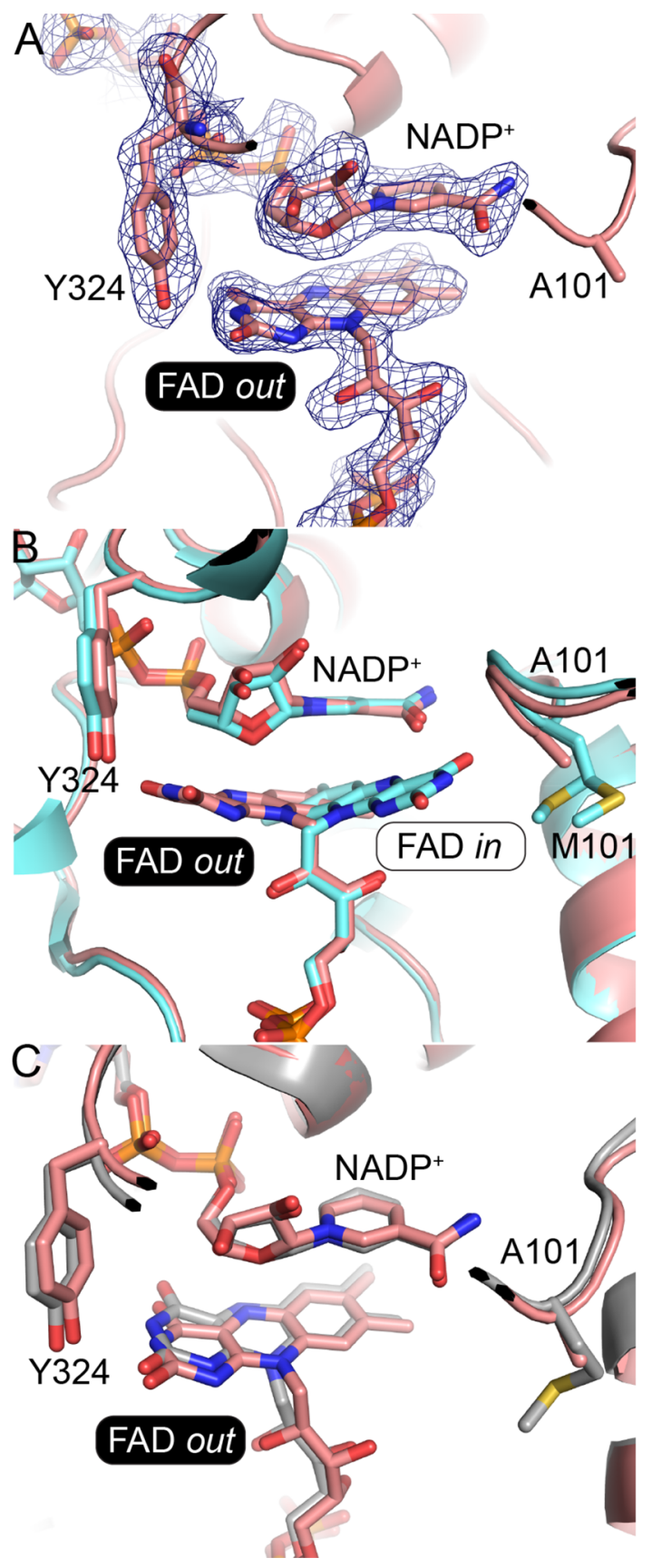

Figure 5. Structure of M101A complexed with $\mathrm{NADP}^{+}$. (A) Electron density for $\mathrm{FAD}, \mathrm{NADP}^{+}$, and Tyr324 (polder omit, 3 $\sigma$ ). (B) Comparison of the $\mathrm{NADP}^{+}$complexes of M101A (salmon) and wildtype SidA (aquamarine, PDB entry 6XOI). (C) Comparison of the $\mathrm{NADP}^{+}$complexes of M101A (salmon) and wild-type KtzI (gray, PDB entry 4TLZ).

387 by which these enzymes regulate the reactivity of the flavin 388 cofactor has been the subject of intense investigation for 389 several decades. As a result, many important aspects are 390 currently known. For example, members of the class A flavin 391 monooxygenase are single-component systems that contain a 392 tightly bound FAD. In the substrate-free form, the FAD is 393 buried, and substrate binding triggers a conformational change 394 that exposes the isoalloxazine ring to the surface of the protein 395 where NADPH can interact and transfer a hydride equivalent. 396 This is known as the swinging flavin. ${ }^{26}$ This type of mechanism 397 used by class A monooxygenases has been coined "cautious enzymes" because reaction with NADPH occurs only when the 398 substrate is ready for hydroxylation in the active site, which 399 ensures coupling of the reactions. ${ }^{6,25,26}$ Class B monooxyge- 400 nases contain two Rossmann folds, one each for flavin and 401 NADPH binding. These enzymes use a "bold mechanism", 402 where the enzyme is reduced by $\mathrm{NADPH}$, in the absence of a 403 substrate. Furthermore, $\mathrm{NADP}^{+}$remains bound to the enzyme 404 to stabilize the C4a-hydroperoxyflavin until a suitable substrate 405 binds. $^{6}$

The structures of SidA and PvdA with L-Orn bound in the 407 active site provided the first view of how class B 408 monooxygenases organize a flavin, $\operatorname{NADP}(\mathrm{H})$, and L-Orn for 409 catalysis. $^{10,27}$ Mechanistic and computational analysis with 410 SidA showed that interactions of the amide oxygen of 411 $\operatorname{NADP}(\mathrm{H})$ with the flavin N5 atom were key in the 412 stabilization of the C4-hydroperoxyflavin., ${ }^{9,29}$ Recent work 413 on $\mathrm{SidA}^{7}$ and a related enzyme, $\mathrm{KztI}^{8}{ }^{8}$ revealed unprecedented 414 flavin motion in members of the class B monooxygenase 415 family. In both enzymes, the FAD adopts an out conformation 416 in the ligand-free oxidized state, which differs substantially 417 from the in conformation adopted during catalysis (Figure 3). 418

Here, we sought insight into the origins of flavin motion in 419 class B monooxygenases by probing the function of Met101, a 420 residue that contacts the pyrimidine ring of the in FAD. 421 Steady-state kinetic analysis of M101A shows that the activity 422 is significantly impaired. The reduction of activity does not 423 originate from decreased reactivity with $\mathrm{NADPH}$, as the rate 424 constants for flavin reduction were not significantly affected 425 (Table 3). These results are consistent with the structure of the 426 resting M101A being nearly identical to that of the wild-type 427 enzyme.

Our data suggest that the catalytic defect of M101A 429 originates in events occurring after flavin reduction, in the 430 oxidative half-reaction. It has been previously shown that the 431 $\mathrm{p} K_{\mathrm{a}}$ of the flavin N5 atom in SidA is modulated to stabilize the 432 C4a-hydroperoxyflavin or to facilitate flavin oxidation. ${ }^{24} \mathrm{We} 433$ determined the $\mathrm{p} K_{\mathrm{a}}$ values for M101A in the absence of L-Orn, 434 which represents flavin oxidation by $\mathrm{H}_{2} \mathrm{O}_{2}$ release, and in the 435 presence of L-Orn, which reports on flavin oxidation by 436 dehydration (Figure 2, step 6). The results show no significant 437 changes in the $\mathrm{p} K_{\mathrm{a}}$ values upon mutation of Met101. To 438 determine if the chemical steps involved in flavin oxidation 439 were affected, we performed SKIE experiments. The SKIE 440 values were lower for $\mathrm{H}_{2} \mathrm{O}_{2}$ release (in the absence of L-Orn) 441 and marginally lower for flavin dehydration (in the presence of 442 L-Orn). Thus, a step that occurs at the same time or after these 443 chemical steps is the slow step in the reaction for M101A. 444

We suggest that our kinetic and structural data are consistent 445 with the mutation of Met101 affecting $\mathrm{NADP}^{+}$release. Kinetic 446 data implicate a bottleneck in step 6 of Figure 2, which 447 involves flavin dehydration and the release of $N^{5}$-hydroxy-L- 448 Orn and $\mathrm{NADP}^{+}$. The structure of ligand-free M101A is very 449 similar to that of wild-type SidA, consistent with M101A 450 exhibiting wild-type affinity for NADPH and normal flavin 451 reduction kinetics. In contrast, the structure of the M101A- 452 $\mathrm{NADP}^{+}$complex unexpectedly shows the $\mathrm{FAD}$ in the out 453 conformation. This complex may represent a stalled con- 454 formation that leads to the slow kinetics observed for M101A. 455 This interpretation is in agreement with the proposal of Setser 456 et al. that the purpose of the FAD conformational change from 457 in to out is to eject $\mathrm{NADP}^{+}$in the last step of catalysis. ${ }^{8} 458$

The M101A-NADP ${ }^{+}$complex perhaps represents a dead- 459 end state that is avoided by the wild-type enzyme but is made 460 
461 more accessible by the M101A mutation. Why M101A 462 encourages the dead-end complex is unknown, but one 463 possibility is that Met101 influences enzyme dynamics in the 464 final step of the mechanism (step 6, Figure 2). Step 6 involves 465 an orchestrated sequence of events involving motion of $466 \mathrm{NADP}^{+}, \mathrm{FAD}$, and the Tyr loop. The structures of the wild467 type enzyme complexed with $\mathrm{NADP}^{+}$reveal steric blocks that 468 must be resolved for the enzyme to return to the resting state. 469 The structures suggest that $\mathrm{NADP}^{+}$must dissociate first to 470 allow enough room for the $\mathrm{FAD}$ to rotate around its $\mathrm{C1}^{\prime}-\mathrm{C} 2^{\prime}$ 471 and N10-C1' bonds into the out conformation. Finally, the 472 Tyr loop moves to cover the re-face of the out FAD, as shown 473 in Figure 3 (yellow). Apparently, Met101 plays a role in this 474 sequence of molecular motions. We note that Met101 adopts 475 two different side chain conformations in SidA structures, 476 including dual conformations in the $\mathrm{NADP}^{+}$complex (Figure $4775 \mathrm{~B}$, aquamarine), which indicates that Met101 is flexible. Our 478 work suggests that this flexibility may have a purpose in 479 resetting the enzyme to its resting state. Another possibility is 480 that Met101 helps stabilize the in conformation by acting as a 481 guide that facilitates hydrogen bonding of the pyrimidine edge 482 of the isoalloxazine (Figure 3). Without Met101, the FAD may 483 be more prone to slipping into the out state prior to the release 484 of $\mathrm{NADP}^{+}$, resulting in the dead-end state observed in crystallo. 485 In this scenario, Met101 may help control the order of protein 486 and flavin motions that are needed for proper product release 487 and resetting the enzyme for the next round of catalysis.

\section{ASSOCIATED CONTENT}

\section{SI Supporting Information}

490 The Supporting Information is available free of charge at 491 https://pubs.acs.org/doi/10.1021/acs.biochem.0c00783.

492 Table S1 and Figures S1-S7 (PDF)

\section{Accession Codes}

494 SidA protein, E9QYP0 (UniProt); SidA M101A resting state, 495 7JVK (PDB); SidA M101A complexed with $\mathrm{NADP}^{+}$, 7JVL 496 (PDB).

\section{AUTHOR INFORMATION}

\section{Corresponding Authors}

499 Pablo Sobrado - Department of Biochemistry and Center for

500 Drug Discovery, Virginia Tech, Blacksburg, Virginia 24061,

501 United States; (1) orcid.org/0000-0003-1494-5382;

Email: psobrado@vt.edu

John J. Tanner - Department of Biochemistry and Department of Chemistry, University of Missouri, Columbia, Missouri 65211, United States; (1) orcid.org/0000-00018314-113X; Email: tannerjj@missouri.edu

\section{Authors}

508 Ashley C. Campbell - Department of Biochemistry, University 509 of Missouri, Columbia, Missouri 65211, United States; (1) orcid.org/0000-0002-0178-4017

Reeder Robinson - Department of Biochemistry and Center for Drug Discovery, Virginia Tech, Blacksburg, Virginia 24061, United States

Didier Mena-Aguilar - Department of Biochemistry and Center for Drug Discovery, Virginia Tech, Blacksburg, Virginia 24061, United States

517 Complete contact information is available at: 518 https://pubs.acs.org/10.1021/acs.biochem.0c00783

\section{Author Contributions}

A.C.C. performed X-ray diffraction experiments and structure 520 refinement. D.M.-A. performed protein purification. R.R. 521 performed site-directed mutagenesis and kinetic studies. 522 A.C.C. and D.M.-A. performed crystallization. J.J.T. and P.S. 523 wrote the initial draft of the manuscript. All authors analyzed 524 data and reviewed the final version of the manuscript. 525

\section{Funding}

This research was supported by National Science Foundation 527 Grants CHE-2003658 (to P.S.) and CHE-2003986 (to J.J.T.). 528

Notes

The authors declare no competing financial interest.

\section{ACKNOWLEDGMENTS}

530

The authors thank Hanna Valentino for help with data analysis 532 and J. Nix for help with remote X-ray diffraction data collection 533 at beamline 4.2.2. Beamline 4.2.2 of the Advanced Light 534 Source, a U.S. Department of Energy Office of Science User 535 Facility under Contract DE-AC02-05CH11231, is supported in 536 part by the ALS-ENABLE program funded by the National 537 Institutes of Health, National Institute of General Medical 538 Sciences, Grant P30 GM124169-01.

\section{ABBREVIATIONS}

540

L-Orn, L-ornithine; SidA, siderophore biosynthetic enzyme A; 541 NMO, N-hydroxylating flavin-dependent monooxygenase; 542 PDB, Protein Data Bank; SKIE, solvent kinetic isotope effect. 543

\section{REFERENCES}

544

(1) Hissen, A. H., Wan, A. N., Warwas, M. L., Pinto, L. J., and 545 Moore, M. M. (2005) The Aspergillus fumigatus siderophore 546 biosynthetic gene sidA, encoding L-ornithine N5-oxygenase, is 547 required for virulence. Infect. Immun. 73, 5493-5503.

548

(2) Chocklett, S. W., and Sobrado, P. (2010) Aspergillus fumigatus 549 SidA is a highly specific ornithine hydroxylase with bound flavin 550 cofactor. Biochemistry 49, 6777-6783.

551

(3) Martín Del Campo, J. S., Vogelaar, N., Tolani, K., Kizjakina, K., 552 Harich, K., and Sobrado, P. (2016) Inhibition of the Flavin- 553 Dependent Monooxygenase Siderophore A (SidA) Blocks Side- 554 rophore Biosynthesis and Aspergillus fumigatus Growth. ACS Chem. 555 Biol. 11, 3035-3042.

(4) Romero, E., Fedkenheuer, M., Chocklett, S. W., Qi, J., 557 Oppenheimer, M., and Sobrado, P. (2012) Dual role of NADP(H) 558 in the reaction of a flavin dependent N-hydroxylating monooxygenase. 559 Biochim. Biophys. Acta, Proteins Proteomics 1824, 850-857. 560

(5) Haas, H. (2014) Fungal siderophore metabolism with a focus on 561 Aspergillus fumigatus. Nat. Prod. Rep. 31, 1266-1276.

(6) Palfey, B. A., and McDonald, C. A. (2010) Control of catalysis in 563 flavin-dependent monooxygenases. Arch. Biochem. Biophys. 493, 26- 564 36.

(7) Campbell, A. C., Stiers, K. M., Martin Del Campo, J. S., Mehra- 566 Chaudhary, R., Sobrado, P., and Tanner, J. J. (2020) Trapping 567 conformational states of a flavin-dependent $\mathrm{N}$-monooxygenase in 568 crystallo reveals protein and flavin dynamics. J. Biol. Chem. 295, 569 13239-13249.

(8) Setser, J. W., Heemstra, J. R., Jr., Walsh, C. T., and Drennan, C. 571 L. (2014) Crystallographic evidence of drastic conformational 572 changes in the active site of a flavin-dependent $\mathrm{N}$-hydroxylase. 573 Biochemistry 53, 6063-6077.

(9) Robinson, R., Badieyan, S., and Sobrado, P. (2013) C4a- 575 hydroperoxyflavin formation in $\mathrm{N}$-hydroxylating flavin monooxyge- 576 nases is mediated by the $2^{\prime}-\mathrm{OH}$ of the nicotinamide ribose of 577 $\operatorname{NADP}(+)$. Biochemistry 52, 9089-9091.

(10) Franceschini, S., Fedkenheuer, M., Vogelaar, N. J., Robinson, 579 H. H., Sobrado, P., and Mattevi, A. (2012) Structural insight into the 580 
581 mechanism of oxygen activation and substrate selectivity of flavin582 dependent N-hydroxylating monooxygenases. Biochemistry 51, 70435837045 .

584 (11) Crooks, G. E., Hon, G., Chandonia, J. M., and Brenner, S. E. 585 (2004) Web Logo: a sequence logo generator. Genome Res. 14, 11885861190

587 (12) Chocklett, S. W., and Sobrado, P. (2010) Aspergillus fumigatus 588 SidA Is a Highly Specific Ornithine Hydroxylase with Bound Flavin 589 Cofactor. Biochemistry 49, 6777-6783.

590 (13) Csaky, T. Z., Hassel, O., Rosenberg, T., Lang, S., Turunen, E., 591 and Tuhkanen, A. (1948) On the estimation of bound hydroxylamine 592 in biological materials. Acta Chem. Scand. 2, 450-454.

593 (14) Schowen, K. B., and Schowen, R. L. (1982) Solvent isotope 594 effects of enzyme systems. Methods Enzymol. 87, 551-606.

595 (15) Kabsch, W. (2010) XDS. Acta Crystallogr., Sect. D: Biol. 596 Crystallogr. 66, 125-132.

597 (16) Evans, P. R., and Murshudov, G. N. (2013) How good are my 598 data and what is the resolution? Acta Crystallogr., Sect. D: Biol. 599 Crystallogr. 69, 1204-1214.

600 (17) Luo, M., Gamage, T. T., Arentson, B. W., Schlasner, K. N., 601 Becker, D. F., and Tanner, J. J. (2016) Structures of Proline 602 Utilization A (PutA) Reveal the Fold and Functions of the Aldehyde 603 Dehydrogenase Superfamily Domain of Unknown Function. J. Biol. 604 Chem. 291, 24065-24075.

605 (18) Afonine, P. V., Grosse-Kunstleve, R. W., Echols, N., Headd, J. 606 J., Moriarty, N. W., Mustyakimov, M., Terwilliger, T. C., Urzhumtsev, 607 A., Zwart, P. H., and Adams, P. D. (2012) Towards automated 608 crystallographic structure refinement with phenix.refine. Acta 609 Crystallogr., Sect. D: Biol. Crystallogr. 68, 352-367.

610 (19) Emsley, P., Lohkamp, B., Scott, W. G., and Cowtan, K. (2010) 611 Features and development of Coot. Acta Crystallogr., Sect. D: Biol. 612 Crystallogr. 66, 486-501.

613 (20) Chen, V. B., Arendall, W. B., 3rd, Headd, J. J., Keedy, D. A., 614 Immormino, R. M., Kapral, G. J., Murray, L. W., Richardson, J. S., and 615 Richardson, D. C. (2010) Mol Probity: all-atom structure validation 616 for macromolecular crystallography. Acta Crystallogr., Sect. D: Biol. 617 Crystallogr. D66, 12-21.

618 (21) Gore, S., Sanz Garcia, E., Hendrickx, P. M. S., Gutmanas, A., 619 Westbrook, J. D., Yang, H., Feng, Z., Baskaran, K., Berrisford, J. M., 620 Hudson, B. P., Ikegawa, Y., Kobayashi, N., Lawson, C. L., Mading, S., 621 Mak, L., Mukhopadhyay, A., Oldfield, T. J., Patwardhan, A., Peisach, 622 E., Sahni, G., Sekharan, M. R., Sen, S., Shao, C., Smart, O. S., Ulrich, 623 E. L., Yamashita, R., Quesada, M., Young, J. Y., Nakamura, H., 624 Markley, J. L., Berman, H. M., Burley, S. K., Velankar, S., and 625 Kleywegt, G. J. (2017) Validation of Structures in the Protein Data 626 Bank. Structure 25, 1916-1927.

627 (22) Liebschner, D., Afonine, P. V., Moriarty, N. W., Poon, B. K., 628 Sobolev, O. V., Terwilliger, T. C., and Adams, P. D. (2017) Polder 629 maps: improving OMIT maps by excluding bulk solvent. Acta 630 Crystallogr. D Struct Biol. 73, 148-157.

631 (23) Romero, E., Fedkenheuer, M., Chocklett, S. W., Qi, J., 632 Oppenheimer, M., and Sobrado, P. (2012) Dual role of NADP $(\mathrm{H})$ in 633 the reaction of a flavin dependent N-hydroxylating monooxygenase. 634 Biochim. Biophys. Acta, Proteins Proteomics 1824, 850-857.

635 (24) Robinson, R. M., Klancher, C. A., Rodriguez, P. J., and Sobrado, 636 P. (2019) Flavin oxidation in flavin-dependent $\mathrm{N}$-monooxygenases. 637 Protein Sci. 28, 90-99.

638 (25) Huijbers, M. M., Montersino, S., Westphal, A. H., Tischler, D., 639 and van Berkel, W. J. (2014) Flavin dependent monooxygenases. 640 Arch. Biochem. Biophys. 544, 2-17.

641 (26) Ballou, D. P., Entsch, B., and Cole, L. J. (2005) Dynamics 642 involved in catalysis by single-component and two-component flavin643 dependent aromatic hydroxylases. Biochem. Biophys. Res. Commun. $644338,590-598$.

645 (27) Olucha, J., Meneely, K. M., Chilton, A. S., and Lamb, A. L. 646 (2011) Two structures of an N-hydroxylating flavoprotein mono647 oxygenase: ornithine hydroxylase from Pseudomonas aeruginosa. J. 648 Biol. Chem. 286, 31789-31798.
(28) Shirey, C., Badieyan, S., and Sobrado, P. (2013) Role of Ser- 649 257 in the sliding mechanism of $\mathrm{NADP}(\mathrm{H})$ in the reaction catalyzed 650 by the Aspergillus fumigatus flavin-dependent ornithine N5- 651 monooxygenase SidA. J. Biol. Chem. 288, 32440-32448.

(29) Badieyan, S., Bach, R. D., and Sobrado, P. (2015) Mechanism 653 of N-hydroxylation catalyzed by flavin-dependent monooxygenases. J. 654 Org. Chem. 80, 2139-2147. 